are of enormous potential consequence, given the prevalence of ischaemic heart disease and hypercholesterolaemia in Britain alone. Many hundreds of thousands of patients could require cholesterol lowering drugs once dietary advice has failed. Given the magnitude of the problem, do we need more evidence that such results can be generalised before we embark on this colossal task?

\section{J HIPPISLEY-COX}

Crookes, Trainee general practitione

Sheffield S10 1LF

1 Oliver M, Poole-Wilson $M$. Shepherd J, Tikkanen M. Lowe patients' cholesterol now. BMf 1995;310:1280-1. (20 May.)

2 Ferner RE, Neill HAW. A suitable case for treatment. Lance 1995;345:1051.

\section{Occupational health: undefined, under reported, and uncompensated}

\section{Definitions of disease categories are important}

EdrToR,-D Sen and K Osborne highlight the fact that occupational disease is underreported and possibly underdiagnosed by general practitioners. They fail, however, to try to rectify the situation by giving the correct definitions of notifiable, prescribed, and reportable diseases. It would be advantageous if articles criticising doctors for lack of knowledge of important definitions included these definitions. Brief definitions are as follows. ${ }^{2}$

Notifiable infectious diseases (under the Public Health Act 1984) must be reported by the doctor to the local authority. Examples include acute meningitis, infected jaundice, measles, tetanus, and tuberculosis. A full list is given by Kloss. ${ }^{2}$

Prescribed diseases are specific diseases related to work that are prescribed for particular occupations by the secretary of state in regulations. Sufferers can claim benefit. An example of a prescribed occupational disease is carcinoma of the lung, with evidence of asbestosis, when the sufferer has worked in a specific occupation with asbetos. Another example is vibration white finger when the person has worked in a specific occupation using handheld power drills or other specified equipment.

Reportable diseases are those diseases related to work that must be reported under the Reporting of Injuries, Diseases and Dangerous Occurrence Regulations, ${ }^{3}$ which are currently being updated. It is the employer's duty to report these diseases if he or she has received a written diagnosis on an employee from a doctor-for example, a medical certificate. Reporting the disease does not necessarily mean that it was caused by work and does not allow the person to claim any benefit. Two examples of reportable diseases are decompression sickness and leptospirosis.

There are 28 reportable diseases and 39 prescribed diseases. Not all reportable diseases are prescribed, and most, but not all, prescribed diseases are reportable. Consequently the two lists of reportable and prescribed diseases overlap considerably, and for patients to gain any benefit from the state they must prove that they worked in a specific occupation that resulted in their disease.

ELIZABETH M FISHER
Area occupational health physician, Marks and Spence Horsham RH12 2PP

1 Sen $\mathrm{D}$, Osborne $\mathrm{K}$. General practitioners' knowledge of notifiable, reportable, and prescribed diseases. BMf 1995;310 1299. (20 May.)

2 Kloss D. Occupational health law. Oxford: Blackwell Scientific, 1989.

3 Reporting of injuries, diseases and dangerous occurrences regulation (RIDDOR). London: HMSO, 1985

4 Health and Safety Commission. Draft proposals for the reporting of injuries, diseases and dangerous occurrences regulations 1990Sudbury, Suffolk: HSE Books, 1994
Occupational health pilot study finds unmet need

EDrTor,-We endorse Anthony Seaton's suggestions regarding occupational medicine, ${ }^{1}$ but the current staffing and structure of the NHS occupational health departments seem unlikely to be able to meet the demands of their surrounding communities. What is to happen in the interim?

Our pilot occupational health project found that $61(13 \%)$ of 474 patients interviewed in general practice surgeries were visiting their general practitioner because of health problems related to work; this is higher than the national findings $(7 \%)$ reported by the Health and Safety Executive. ${ }^{23}$ Altogether 191 of the patients interviewed reported ill health resulting from their current or previous jobs, and 400 of the patients reported their lack of access to an occupational health service.

Providing only an outpatient referral service for local doctors as a measure to improve the mechanisms for managing ill health related to work will be inadequate. Programmes to increase awareness among general practitioners are needed, as highlighted by D Sen and K Osborne. ${ }^{4}$ Such programmes would not only enable doctors to identify cases that require referral but also prevent possible conflicts that could arise between general practitioners and occupational physicians.

Given the current emphasis on diagnosis and treatment in the community and primary care settings, occupational health services based in primary care should be supported and developed. At present such services exist as occupational health projects and are mostly funded by the local family health services and district health authorities. There are two in London, four in Yorkshire, one in Liverpool, and one planned for Scotland. They raise awareness of occupational health issues among primary care staff and their patients through interviewing patients and eliciting occupational histories, which become part of the patients' medical records. They also provide interactive feedback with case studies at practice meetings, information, seminars, and advice and support issues such as benefits. In view of the promising evaluations of these projects, making advice on occupational health standard practice in primary care settings should be considered seriously.

R ISANEDIGHI Occupational health project worke JMANNALI Public health specialis

Health promotion strategist J HARVEY

Public Health Directorate,

East London and the City Health Authority,

London E3 2AN

GEDER

Department of General Practice and Primary Care,

St Bartholomew's Hospital

London EC1A 7BE

Seaton A. Diagnosing and managing occupational disease. $B M \mathcal{F}$ 995;310:1282. (20 May.)

2 Isanedighi RO. An occupational health project in the east end-a report. London: East London and the City Health Authority, 1994.

3 Health and Safety Executive. Your patients and their work. An introduction to occupational health for family doctors. Sudbury, Suffolk: HSE Books, 1992

4 Sen D, Osborne K. General practitioners' knowledge of notifiable, reportable, and prescribed diseases. $B M \mathcal{F} 1995 ; 310$ 1299. (20 May.)

5 Gration JCD. Effective occupational health-difficulties of delivery. Occup Med 1995;45:61-2.

\section{Prescribed diseases yield substantial compensation}

EDITOR,-S C Stenton and colleagues suggest that medical practitioners underrefer patients with occupational asthma, ${ }^{1}$ while D Sen and K Osborne have gathered evidence highlighting general practitioners' lack of knowledge about prescribed diseases. ${ }^{2}$ Both papers mention briefly that people diagnosed as having a prescribed disease are eligible to claim disability benefit.

The disability benefit awarded to such people can be substantial, especially if they are also awarded a linked benefit, reduced earnings allowance. This is particularly so with diseases such as asthma, byssinosis, and asbestosis, which can often be diagnosed only on the basis of a detailed work history taken several years after the onset of the disease. Three of my own recent cases serve as examples: a client deemed to have had byssinosis for the past 30 years obtained $£ 15000$ in arrears of disablement benefit and a continuing award of nearly $£ 30$ a week; a client diagnosed as having had asbestosis for 20 years was awarded $£ 16000$ in arrears of benefits and $£ 60$ a week; and a client with dermatitis was awarded $£ 3000$ in arrears and $£ 20$ a week.

Many people like these retire early on grounds of ill health, are in poor health, and exist on state benefits. Disability benefit can help them to spend their retirement more comfortably. For some, however, the route to being awarded disability benefit is not easy. The three clients referred to above were successfut only after taking their cases to a medical appeal tribunal, which overturned the Department of Social Security's initial decision that they did not suffer from any of the prescribed diseases.

Increased awareness of prescribed diseases should increase the uptake of disability benefit. It should also result in more successes at the point of claim so that fewer claimants are faced with what for many is a lengthy and daunting appeal procedure. Once a diagnosis has been made, people then require sound advice on benefits, particularly when large awards are at stake. Some citizens advice bureaus have developed links with their local general practitioners. In Rochdale we hold regular advice sessions at three local practices and I have had several productive referrals from local general practitioners. While closer liaison between the Benefits Agency and other medical services might be one approach, ${ }^{2}$ having and using a high profile advice agency on the doorstep might also be useful.

JULIA WILKINSON

Rochdale Citizens Advice Bureau,

Welfare benefits

Rochdale OL16 1RS

Stenton SC, Sandhu PS, Hendrick DJ. Industrial injury benefit for occupational asthma in north east of England. $B M$ 1995;310:1299-300. (20 May.)

2 Sen D, Osborne K. General practitioners' knowledge of notifiable, reportable, and prescribed diseases. $B M \mathcal{F} 1995 ; 310$ 1299. (20 May.)

\section{Incidence of toxoplasma retinochoroiditis}

EDITOR,-R E Gilbert and colleagues offered a new insight into the incidence of toxoplasma retinochoroiditis, but raised some doubts.' The fascination is that the results are different from previous reports, ${ }^{2}$ which has implications for the management of toxoplasma infection in pregnancy.

The study methods should be carefully examined. Ophthalmologists were required to notify cases of toxoplasma retinochoroiditis to the researchers. Ophthalmologists are busy people and the help of none was acknowledged, so the study's results depended on the altruism of the participants. Three of the nine units reported no cases, which is a bit surprising, but the distribution of patients does seem to reflect a geographical sphere of influence of the researchers. There can be great inaccuracies with voluntary reporting. In Scotland toxoplasmosis is a notifiable disease through a 